\title{
MUDANÇAS NA VIDA E NO CORPO: VIVÊNCIAS DIANTE DA GRAVIDEZ NA PERSPECTIVA AFETIVA DOS PAIS
}

\author{
Changes in the life and in the body: Experiences before the \\ pregnancy in the affective perspective of parents. \\ Cambios en la vida y en el cuerpo: experiencias frente al embarazo \\ en la perspectiva afectiva de los padres.
}

\section{RESUMO}

Pesquisa do tipo descritivo-exploratório, com abordagem qualitativa, que teve como objetivos: descrever as vivências destacadas pelos pais diante da gravidez e analisar tais vivências sob a perspectiva da afetividade, construída pelos pais diante da gravidez. Os participantes foram seis mães e três pais. A técnica de coleta utilizada foi a entrevista em profundidade. Os dados foram submetidos à análise pela modalidade temática, emergindo duas categorias: Vivendo intensas mudanças na vida e Vivendo intensas mudanças no corpo. Concluiu-se que, na gestação, os enfrentamentos podem oscilar em momentos de desequilíbrio e outros de superação. Nesse entremeio, a afetividade está ligada a essas respostas adaptativas dos pais e da família.

Palavras-chave: Afeto. Gravidez. Família. Enfermagem.

\begin{abstract}
Research of the descriptive and exploratory type, with qualitative approach that had as objectives: describe the experiences detached by parents before the pregnancy and, to analyze these experiences from the perspective of affectivity, built by parents before the pregnancy. The participants had been six mothers and three fathers. The collection technique used was the interview in depth. The data had been submitted to the analysis for the thematic modality, emerging two categories: Living intense changes in life e; Living intense changes in the body. It is concluded that in the gestation, the confrontations can oscillate at disequilibrium moments and others of overcoming. In this way, the affectivity is connected to adaptive responses of the parents and the family.
\end{abstract}

Keywords: Affect. Pregnancy. Family. Nursing

\section{Resumen}

Investigación del tipo descriptivo y exploratorio, con abordaje cualitativo que tenía como objetivos: Describir las experiencias de relieve por los padres enfrente del embarazo y, Examinar esas experiencias desde la perspectiva de la afectividad, construido por los padres enfrente del embarazo. Los participantes fueron seis madres y tres padres. La técnica de colecta fue la entrevista en profundidad. Los datos habían sido presentados al análisis por la modalidad temática, emergiendo dos categorías: Viviendo intensos cambios en la vida y; Viviendo intensos cambios en el cuerpo. Se concluye que en la gestación, las confrontaciones pueden oscilar en los momentos del desequilibrio y otros de superación. De esta manera, la afectividad está conectada a esas respuestas adaptantes de los padres y de la familia.

Palabras clave: Afecto. Embarazo. Familia. Enfermería.

${ }^{1}$ Mestre em enfermagem. Enfermeira da Maternidade-Escola da Universidade Federal do Rio de Janeiro - UFRJ, Rio de Janeiro/RJ. Brasil. E-mail: lauraenfa@yahoo.com.br, ${ }^{2}$ Doutora em Enfermagem. Professora Adjunta do Departamento de Enfermagem Materno-Infantil da Escola de Enfermagem Alfredo Pinto. Coordenadora do Núcleo de Pesquisa, Experimentação e Estudos em Enfermagem na Área da Mulher e da Criança (NuPEEMC), Universidade do Estado do Rio de Janeiro - UNIRIO, Rio de Janeiro/RJ. Brasil. E-mail: Irangel@rio.com.br 


\section{INTRODUÇÃO}

0 presente estudo foi desenvolvido na linha de pesquisa Cuidado em Enfermagem - o cotidiano da prática de cuidar e ser cuidado e está inserido no Núcleo de Pesquisa, Experimentação e Estudos em Enfermagem na Área da Mulher e da Criança (NuPEEMC), da Escola de Enfermagem Alfredo Pinto, da Universidade Federal do Estado do Rio de Janeiro (UNIRIO) .

Sabe-se que a gestação é um evento importante nas vivências familiares, com grandes repercussões na constituição da família e na formação de laços afetivos entre seus membros, principalmente dos pais com os filhos. Ao levar em consideração a psicodinâmica da gravidez, este período pode ser considerado uma situação de crise evolutiva, ou seja, que faz parte do processo normal de desenvolvimento do ser humano. A caracterização fundamental de 'crise' implica na resposta adaptativa na vida da pessoa, diante da emergência de novos fatos, naturais ou acidentais - neste caso, a gravidez. Tal resposta adaptativa, exigida pela nova situação, está envolta por demandas afetivas, estruturais, econômicas, familiares e sociais nas quais pode existir a superação ou o desequilibrio'.

A experiência de gerar um filho é um momento de destaque no ciclo vital da mulher e do homem com repercussões importantes para seus meios familiares. Assim, a gestação, invariavelmente, é um período de intensas mudanças no corpo e na psique da mulher, além das expectativas, planos e projetos desenvolvidos pela família. Tal processo de significação está intrinsecamente ligado ao envolvimento psicoafetivo da unidade familiar.

Ao longo do tempo, as configurações relacionais da família têm sofrido modificações. Estas, por sua vez, estão imbricadas com o conjunto de transformações socioeconômicas complexas e aceleradas das últimas décadas, que repercutiu no mundo do trabalho, dos costumes, dos valores, das condições de reprodução e das posições sociais e culturais do homem e da mulher. Isso certamente atinge o exercício da maternidade e da paternidade e a própria constituição da família².

Apesar das intensas mudanças ocorridas em sua estrutura e organização, a família continua como uma unidade que cuida de seus membros, sendo responsável pelo atendimento de suas necessidades básicas, assim como pela formação dos referenciais de vida.

$\mathrm{Na}$ gestação, os pais precisam elaborar afetivamente 0 cuidado materno/paterno com o qual irão proteger e amparar a criança que está por vir. Assim, a família é o grupo social responsável pelo cuidado familial, que, por sua vez, é um processo aprendido e construído pela família em sua trajetória, que inclui vários atributos: presença, inclusão, promoção da vida e bem-estar, proteção e orientação para a vida. Dentre estes, destaca-se a presença, como um elemento constitutivo essencial que envolve a solidariedade entre os membros da família por meio de ações, interações e interpretações. Está ligada à capacidade de ouvir, dialogar, acompanhar e comprometer-se com o outro; portanto, a 'presença', enquanto elemento do cuidado familial, é fundamental em todas as fases da vida humana ${ }^{3-4}$.

As experiências mais profundas da vida dos seres humanos são sempre marcadas por fortes emoções. Geralmente, a emoção é analisada pelo seu componente orgânico-corpóreo, ou seja, pelas evidentes reações quando se experimenta um estado emocional, por exemplo, a aceleração das batidas do coração, do ritmo respiratório e da pressão sanguínea, além das mudanças tonicofaciais tais como o franzir da testa, a abertura da boca e das pálpebras. Assim, descrevem-se as emoções muito mais com base nos aspectos biológicos do que nos subjetivos. Quanto aos aspectos subjetivos, eles são contemplados na seguinte compreensão: a afetividade compreende as valorações e impressões pessoais que o ser humano atribui a um evento ou experiência, assim ele 'sente' para si mesmo um universo repleto de significados próprios e subjetivos que são afetados pelos meios externo e interno ${ }^{5}$.

Assim, a reflexão que se torna possível fazer é de que a afetividade consegue agrupar, dinamicamente, as respostas do corpo, as emoções e os significados que despontam no psiquismo humano. Isso confere qualidade aos relacionamentos que o homem estabelece consigo mesmo, com os outros e com seu meio, e dificilmente pode ser mensurado, dada a complexidade traduzida nos afetos.

Esses relacionamentos se traduzem na vivência, que é caracterizada como a unidade estrutural entre formas de atitude e conteúdos, implicando, portanto, a consciência do vivido. A vivência agrupa em si mesma os processos intelectuais da concepção do objeto e os processos afetivos envolvidos na atribuição de valor, bem como o estabelecimento de fins. Logo, a vivência é tecida em meio a uma atmosfera de valores, significados, expressões, ideias e ideais concebidos pelo ser humano em suas relações subjetivas e intersubjetivas no mundo 6 .

Neste estudo, o objeto delimitado para investigação se constituiu nas vivências dos pais diante da gravidez. Os objetivos delineados foram: descrever as vivências destacadas pelos pais diante da gravidez e analisar tais vivências sob a perspectiva da afetividade, construída pelos pais diante da gravidez.

A importância de pesquisar este objeto pauta-se na compreensão holística da gravidez como um período de intensas transformações e construção da história afetiva familiar, no qual tanto a mulher como o homem são protagonistas em suas ricas vivências. "[...] os indivíduos, na singularidade de suas vivências, coexperimentam valores, objetivos, expressões, significados, crenças e, assim, coparticipam da criação ou construção desse todo a que pertencem e que lhes pertence também"7:57. 


\section{METODOLOGIA}

A abordagem utilizada neste estudo foi a qualitativa. Tal modalidade envolve a utilização de estudos e coleção de uma variedade de materiais empíricos, tais como experiência pessoal, introspecção, história de vida, entrevista, observação, interações, dentre outros. De posse desses materiais empíricos, o pesquisador qualitativo pode descrever rotinas, momentos problemáticos ou significados individuais da vida dos sujeitos ${ }^{7}$.

Configura-se como uma pesquisa do tipo descritivoexploratório por trabalhar com os vários ângulos que influenciam o objeto e focalizar um fenômeno contemporâneo, proporcionando uma descrição aprofundada de suas dimensões e processos essenciais 8 .

Os sujeitos foram seis mães e três pais assistidos na Maternidade-Escola da Universidade Federal do Rio de Janeiro. Cumpre-nos ressaltar que eles foram abordados para a participação no estudo somente após o nascimento do filho. Essa estratégia foi utilizada para que eles pudessem elaborar, emocionalmente, as vivências da gravidez e poder falar livremente sobre elas.

Este estudo atendeu aos aspectos ético-legais ligados à pesquisa com seres humanos, especificados pela Resolução 196/96 do Conselho Nacional de Saúde, uma vez que foi aprovado pelo Comitê de Ética em Pesquisa da referida instituição. 0 projeto foi submetido à avaliação e aprovado em 17 de agosto de 2006, sendo protocolado sob o número 04/ 06. Os sujeitos tiveram acesso ao Termo de Consentimento Livre e Esclarecido em momento anterior à pesquisa, ficando assegurados a ausência de riscos à saúde, 0 anonimato e a veiculação das informaç̃oes concedidas apenas para fins científicos.

Para técnica de coleta de dados foi utilizada a entrevista aberta, ou entrevista em profundidade, que explora cuidadosa e detalhadamente a cosmovisão pessoal do entrevistado. A questão norteadora utilizada foi: Conte-me sobre suas vivências na gravidez. Nesta técnica, as perguntas são abertas, realizadas face-a-face, e o convidam a falar longamente, com suas próprias palavras e com tempo para refletir.

Cabe-nos ressaltar que, nos três casais que participaram do estudo, pai e mãe foram entrevistados juntos; portanto, como forma de identificação, na apresentação das categorias, as falas dos homens estão sublinhadas. A coleta de dados ocorreu nos meses de setembro de 2006 a janeiro de 2007. A captação de sujeitos cessou com base no critério de saturação dos dados. Os depoimentos foram gravados em fitas magnéticas e posteriormente transcritos.

0 tratamento dos dados foi realizado com base em uma das técnicas que compõe a Análise de Conteúdo, a saber, a análise por temas, ou análise temática. Trata-se de uma modalidade que permite a categorização mediante a contagem de temas. Estes são palavras ou frases que formam unidades de codificação, ou seja, de significação ou ainda de sentido para o objeto analítico visado. Eles podem conter em si mesmos dimensões variáveis e complexas.

Assim, a partir de leituras intensivas das transcrições, foi possível identificar a existência de 10 unidades temáticas: Sentir incômodo pelas alterações corporais; Não planejar a gravidez; Desejar ter filhos; Aceitar/enfrentar a gravidez; Preocupar-se com a aceitação e/ou participação da família; Não contar com a presença/apoio do outro (pai); Contar com a presença/apoio da família/amigos; Preocupar-se com as questões econômicas para a criação do filho; Experienciar muitas mudanças na rotina de vida; Passar por muitas alterações do humor. A convergência destas unidades temáticas deu origem aos dois núcleos temáticos, Vida e Corpo, a partir dos quais foram construídas as duas categorias deste estudo: Vivendo intensas mudanças na vida e Vivendo intensas mudanças no corpo.

\section{ANÁLISE E DISCUSSÃO DOS RESULTADOS}

\section{Vivendo intensas mudanças na vida}

Existem momentos vividos pelos pais, anteriores à gestação, que influenciarão diretamente nos elos entre eles e seu bebê, ou seja, na própria formação do vínculo. Tais momentos compõem a pré-história da ligação afetiva. Eles se constituem na própria história afetivo-familiar, ou seja no cuidado que os pais receberam de seus pais, nas relações familiares e conjugais, no planejamento da gravidez e no desejo consciente, ou mesmo inconsciente, de ter filhos ${ }^{9}$.

Eu levei um susto, foi tanto que quando o médico estava fazendo a ultra, ele falou assim: "Ih! Alessandra, não é um só não". [...] Aí ele falou: "são três". [...] Foi um choque mesmo, porque nós planejávamos um só, um só mesmo, né Carlos? [...]A gente queria ligar mesmo com um filho, entendeu? [...] a gente está casado há oito anos e ela não engravidava, [...] na minha cabeça eu falei assim: "não, vai ter uma hora que vai vir um bebê mesmo" e ela não, ela achava que não ia ter nunca [...]. Aí um belo dia, eu fui fazer o exame e estava grávida (ALESSANDRA e CARLOS).

Olha! Foi uma gravidez que não foi planejada, entendeu?! A gente tem que assumir o que a gente faz. E desde o primeiro momento que eu soube, eu fiquei muito feliz, porque eu sempre quis. Eu sempre quis, apesar de não ser o momento, de não estar esperando. [...] pra mim foi muito bom e desdeo primeiro dia que a minha médica falou que eu poderia estar grávida, a menstruação estava atrasada duas semanas, eu fiquei feliz, um pouco preocupada, mas muito mais feliz, muito mesmo (MARIA). 
Não foi planejada, aconteceu. No início queria tirar, meu marido concordou, depois descordou. Quando deu dois meses de gravidez, falou: "Não! Deixa vir porque vai ser menina, eu tenho certeza que vai sermenina, eu sou louco por uma menina". O outro é menino. Aípronto (JADE).

A gravidez dela não foi esperada, não foi planejada. A gente não esperava, mas logo enfrentamos bem, por nós foi tudo bem (MAURICIO).

Esta questão de planejamento da gravidez tem relação mais direta com o desejo dos pais de terem filhos em um determinado período de suas vidas, ou seja, seus planos de formar/crescer ou não o núcleo familiar. No decorrer da vida familial o nascimento do primeiro filho ou de mais um constitui um marco importante no ciclo de desenvolvimento da família, representando sua expansão. 0 momento de gerar os filhos é um dos enfrentamentos mais comuns vividos pelas famílias e portanto considerado uma fase vital do núcleo familial ${ }^{10}$.

Em todas os casos nos quais não houve planejamento, havia um desejo prévio, consciente ou inconsciente, de ter filhos, ou ainda o desejo construído (em si mesmo ou junto ao outro) de gestá-los após a confirmação da gravidez, mesmo não sendo no momento desejado. Esta compreensão é confirmada pelo enfrentamento das situações relatadas pelos sujeitos, principalmente pelas mães. Diante da constatação da gravidez e do desejo de levá-la adiante, os pais passam por vários arranjos e superações na vida pessoal e familiar, envolvendo também aspectos afetivos. Neste sentido, a aceitação da gravidez pela família foi uma preocupação constante entre os entrevistados.

Eu gostei né! Só que ela ficou em dúvida se eu ia aceitar ou não a gravidez dela. [...] Foi por causa do meu pai... namorando ainda, então, pra contar pro meu paifoi difíicil. Só que acabou que ele aceitou bem, ele gostou (RITA e ROGÉRIO).

\section{[...] no meu caso fiquei achando 0 que a minha mãe vai falar? Porque pra ela eu era a mais ajuizada da familia e que não ia arrumar um filho assim, do nada, sem planejar mesmo, sem ter uma estrutura. [...] Minhas irmãs também levaram um susto: "0 quê? Juliana grávida? Impossível isso!"; "ela dizia que não ia casar e não ia querer tão cedo filho". [...] Mas eu não tive medo de me criticarem porque na minha consciência, por mais que algumas pessoas acham que não, mas pra mim não importava a opinião de ninguém (JULIANA).}

Esses casais declararam estarem apenas namorando e, por ocasião da descoberta da gravidez, passaram a viver juntos. Embora inesperada, a gravidez antecipou a formação de um núcleo familial, requerendo diferentes enfrentamentos por parte dos pais diante de suas famílias.

Assim, a gravidez pode interferir na natureza do vínculo entre o homem e a mulher, com fortes influências sobre o relacionamento. Alguns casais se aproximam mais, assumindo seus novos papéis e compartilhando as novas necessidades, 0 que fortalece a estrutura familiar. A gravidez se torna um fator alavancador de maiores integrações familiares. Todavia, para outros, a gravidez pode ser um fator desestruturador de relações previamente frágeis, abalando o padrão de interação entre os dois. Então esse redimensionamento familial é importante porque "a mulher, durante a gestação, elabora culturalmente um sentimento de proteção e de amparo na presença da figura paterna"10:124,11

Depreende-se daí que a mulher grávida altera sua própria dimensão afetiva em relação a si mesma, ao feto, ao companheiro e à família. Além disso, as atitudes e respostas masculinas diante da gestação podem variar, indo desde entusiasmo à resistência ou mesmo ambivalência. Então, para o homem, a constatação e a representação da gravidez são diferentes daquelas que são significadas pela mulher.

Eu, sinceramente, desde o início, eu não fiquei, cara! Ela fica até chateada quando eu falo disso, sabe?! [...] Eu não fiquei muito comovido, assim com o fato: ah! Vou ser pail Sabe?! [...] ela ficou super feliz, satisfeita e eu também, mas eu não estava deslumbrado. Normal, entendeu!? [...]. Mas antes quando ela ficou grávida, ficou toda assim né, eu estava feliz mas não estava deslumbrado, como ela estava (CARLOS).

Embora as reações dos pais e familiares à gestação possam ser diferentes, é comum a existência de preocupações e mudanças de planos para a vida, tornando esse período um evento de muita significação, principalmente para os genitores. Frequentemente essas preocupações, por parte dos pais, estão associadas principalmente aos aspectos financeiros para a criação do filho, colocando em questão a estrutura socioeconômica atual e futura do núcleo familiar.

Mas, é pela vida que tinha, eu falava, mas é mais por causa da estrutura né, não ter um emprego bom mesmo pra poder dizer assim: "Ah! Agora posso ter um filho". [...] Mas também fiquei pensando assim: "puxa! Agora eu tô grávida, e aí?" (risos) "Vou ter uma filha, como é que vai ser, né?" Ele não estava trabalhando, como ainda não está. Eu estava trabalhando, mas eu sei que ia ter aquela coisa, talvez ter que deixar o emprego pra poder me dedicar a ela. Mas, apesar dos pesares, a gente conseguiu. Eaí foi a sua mãe (referindo-se a sogra) que ajudou muito, aceitando, dando a maior força 


\section{[...]. Ela está sendo bem-vinda mesmo, por todo mundo (JULIANA).}

Preocupada, preocupada, falei: "Pô! Como éque vai ser? [...] Quem vai olhar pra eu poder voltar a trabalhar? Complicado! Minha filha mais velha, tem mais de quinze anos, vai tomar conta dela pra mim, mora com o pai, mora perto, vai tomar conta dela pra mim voltar a trabalhar normal. Tem que dar um jeito, né (JADE ).

Quando a gente soube que era três, foi um choque, mais pra mim, né?! [...] Daquele dia em diante eu não fui mais o mesmo. E a nossa vida mudou muito mesmo. Porque é aquilo, porque uma coisa é eu trabalhar para sustentar um filho, e dar educação, comida e tudo, dentista, tudo, enfim. A outra coisa é eu fazer isso... nossa! a minha vida já era apertada, financeiramente, daí eu fazer isso tudo para os três, [...] dar um pouco de conforto para eles, como eu vou conseguir fazer isso para os três? E isso não saía da minha cabeça o tempo todo. [...] Então você fala assim: "Caramba! Qual éa base que meus filhos vão ter? [...] Como é que vou dar educação a essas três crianças?" Aí isso tudo na tua cabeça o tempo todo, vinte e quatro horas por dia, [...] eu ficava dirigindo, mas pensando nisso, trabalhando e pensando, comendo e pensando. Eu não falava para ela, né (ALESSANDRA e CARLOS).

Tais preocupações denotam as reflexões que os pais fazem ao dimensionar seu futuro com a chegada do novo membro para compor a família. Suas expressões se voltam à questão primordial de recursos para o sustento e criação dos filhos. Estar desempregado ou com uma estrutura financeira frágil, não saber com quem vai deixar o bebê para voltar a trabalhar, são situações que traduzem as transformações no convívio familiar devido à inclusão de um (ou mais) novo ser, o bebê, que em pouco tempo passará a demandar cuidados especiais, principalmente por parte dos pais. Tais dificuldades podem estar associadas a uma maior vulnerabilidade da criança e da família aos agravos sociais e à saúde, uma vez que esta última é resultante das condições de vida.

É imprescindível compreender que essa pode ser uma fase crítica para algumas pessoas, um período no qual os pais necessitarão realizar arranjos de ordem afetiva, familiar, econômica e social. Essas mudanças necessárias na vida presente e futura podem gerar, por algum tempo, insegurança, medo ou mesmo conflitos internos e também nas relações interpessoais.

Ao aceitar a novidade de estar grávida, a mulher passa por alterações em seu psiquismo que colaboram no processo de maternalidade. Seus sentimentos internos e suas primeiras vivências podem parecer inicialmente contraditórios. Assim, a ambivalência afetiva é comum no perfil psicodinâmico da grávida.

A partir disso, compreende-se que, nessa complexa trama de pensamentos, sentimentos, emoções e climas afetivos, na qual são protagonistas, a mulher, o homem, o feto e suas famílias, seus conteúdos afetivos internos e suas realidades do mundo externo são questionados, por si mesmos e por outros, de modo a concretizar a nova situação e equacionar as intensas vivências desse momento.

Levando-se em consideração a importância do redimensionamento familial, quando a gravidez não é planejada, as histórias vividas por Fabiana e Maria chamam atenção pelo fato de não poderem contar com a presença de um companheiro, que compartilhasse com elas a vida e as responsabilidades de sua nova condição. Fabiana foi violentada sexualmente por um vizinho alcoolizado. Maria, distante de sua família de origem, engravidou numa relação pouco estável e seu parceiro não quis assumir a paternidade. Assim, as dificuldades em contar sobre a gravidez para a família emergiram num contexto de tensão, permeado pela incerteza quanto à aceitação e participação ou o medo da desaprovação e descontentamento por parte dos familiares.

Ah! Demorou cinco meses, quando eu contei, eles acreditaram, mas na hora que meu pai chegou perto dele, ele falou outra coisa. Falou que eu tava me encontrando com ele, essas coisas assim. Aí meu pai falou que não sabe em quem acreditar. Aí eu falei: então não acredita em ninguém, acabou! [...] Mas também eu sofri muito hein?! Sofri muito porque a minha familia sempre falava que eu era uma 'piranha' e que não sei o quê. [...] Agora está tudo bem, agora a minha família sabe de tudo que aconteceu. E agora estão me apoiando porque antes não apoiavam não, jogavam tudo assim na minha cara, se tiver de falar eles falam mesmo. Mas também eu enfrentava eles, não sou de ficar quieta, também! Mas agora tá tudo legal, tá tudo na paz! Graças a Deus! (FABIANA).

[...] a gente namorava há três anos, aí foi meio complicado, a gente começou a brigar muito, porque eu queria e ele não queria, queria que eu tirasse e eu não, isso pra mim era totalmente fora dos meus princípios, da minha vontade. Então, foram meio complicados esses três primeiros meses, na verdade foram por causa disso. Mas, aí, contar pra minha família foi difícil também, porque eu já sabia que ia ser difíil por causa da minha mãe, do meu pai. Mas ela e ele, e os meus irmãos, todos eles me apoiaram desde sempre, desde a primeira hora. Eu levei uns puxõezinhos de orelha da minha 
mãe sim, mas ela me apoiou demais. [...] Eles me ligaram, me apoiaram, estavam prontos pra me ajudar em qualquer coisa que precisasse. [...] Então, eu me fortaleci (MARIA).

Nestes dois relatos, são notáveis os embates emocionais que as mulheres travaram com a família ou com o parceiro para a aceitação da gravidez e a conquista do apoio. De uma forma geral, no contexto do processo cultural atual, a estrutura e a composição legal e solidificada ainda são requisitos para a vinda dos filhos. Então, quando o núcleo familial se encontra estruturado, os desafios e enfrentamentos são encarados de forma mais branda; mas quando essa estrutura não foi constituída e a mulher se encontra na condição de solteira, os enfrentamentos passam a ser divididos por poucos ou nenhum membro da família ${ }^{10}$.

É importante ressaltar que a violência que acontece no espaço privado, doméstico, intrafamiliar, pode ser do tipo psicológica, física, negligência e sexual e ocorre em todas as classes sociais, entre pessoas de diferentes culturas, graus de escolaridade, religião, profissão ou posição política. Fato interessante é que esse tipo de violência, ainda invisível aos olhos da sociedade, é paralelo à violência estrutural, que está intimamente ligada às desigualdades sociais ${ }^{12}$.

Nesse contexto de 'desestrutura' familiar, observa-se uma violência psicológica, dirigida à mulher grávida por meio das palavras e gestos de desaprovação ou descontentamento dos familiares, ou mesmo pela ausência e negligência do homem, em assumir seu papel paterno diante da situação de gravidez. Assim, a violência da mudança brusca da afetividade familiar ou mesmo da ausência do companheiropai no processo de gestação, parto e nascimento, tem influência direta no vínculo mãe-bebê.

Ao relatar suas trajetórias para superar os desafios impostos pela situação, Maria e Fabiana delimitam a gravidez como um período de enfrentamentos e de decisões importantes em relação ao próprio curso da gestação e da vida, um momento para repensar suas relações, seja com o homem-pai ou com o próprio bebê.

Quando eu recebio resultado do exame, que eu falei pra ele [...] Aí ele falou: "Ah! Porque é muito pequenininho ainda, porque não é, não é ..." Eu falei: "é sim, já é uma vida, [...] não vou me tornar uma pessoa criminal por causa da irresponsabilidade minha, não vou, não vou!" [...] Pra ele seria muito mais fácil se eu tirasse. [...] $E$ a gente nunca perde nossos princípios, são coisas que a gente leva pelo resto da vida. Aí preferi manter a distância do pai dela porque a gente não tinha se entendido até então. Aí eu mudei o número do telefone, já tava precisando mudar de casa mesmo [...] Mas a partir do momento que eu parei de falar com ele, aí a coisa começou a melhorar [...]. Eu também estava querendo que ele participasse, entendeu? Mas quando eu percebique não ia acontecer, eu preferi manter a distância. [...] Eu não tinha percebido que ele não era certo pra mim. Foi preciso acontecer isso pra eu perceber (MARIA).

Essas divergências entre o casal denotam uma relação conflituosa quanto aos valores que ambos atribuíram para a vida em formação no ventre e a decisão de tirá-la ou não. Maria chamou esses valores de princípios, no contexto estabelecido por sua própria família e por seu legado de aprendizagem de vida. Sua decisão de levar a gravidez adiante e afastar-se do parceiro foi apoiada pelos familiares.

Teve uma hora que eu fiquei com raiva, sabe, mas ela não tem culpa, ela não pediu pra nascer, né! Mas eu fiquei com uma raiva dele tão grande, eu não converso com ele não [...]. No comecinho eu chorei porque eu não contei pra ninguém. Depois de cinco meses, só depois. [...] Aídepois que ela (referindo-se à madrasta) descobriu que eu estava grávida, ela pensou que eu ia pegar raiva da menina! Eu falava assim: Por que eu vou pegar raiva dela? Ela não tem culpa do que o pai dela fez (FABIANA).

Para Fabiana, o desafio foi aceitar a gestação advinda de uma agressão, ainda em sua adolescência. Em seu posicionamento, ficou notável a não-culpabilização do bebê pela situação indesejada. A disponibilidade afetiva para a aceitação da gravidez possibilitou o início da vinculação mãebebê. São várias as expectativas geradas em torno do bebê; assim, seu futuro estará para sempre comprometido com sua vida intrauterina e com o passado de seus pais, de seus familiares e da sociedade à qual pertence ${ }^{13}$.

Outro aspecto que chamou atenção entre os depoimentos foi a distância física e/ou afetiva entre alguns pais e suas famílias durante a gravidez.

Ah, todo mundo gostou [...] Ninguém ficou assim em cima da gente. É, a nossa família é um pouco assim, meio distante, entendeu? Não por motivo de briga, por nada não, é que hoje em dia cada um tem a sua vida mesmo. Então ninguém deu nenhum tipo de atenção especial. Até hoje a gente não tem, assim, um carinho, isso não existe, mas... Tem mais até pelos amigos, pegam e ligam. Tem uns que estão sempre ligando, ligando várias vezes, "como é que tá? Tá tudo bem?" e tal, vem ver, mais do que a própria família entendeu!? (ALESSANDRA e (ARLOS). 
[...] porque a minha família é distante, eu não tenho, não tive como ver a reação mesmo, olhar assim como eu estou olhando pra você, pra ver dentro dos olhos. Porque a minha mãe mora longe, [...] nem mais indo lá eu tô indo, entendeu?! Até pelo fato de não ter condições também, $e$ transporte também demora muito, a passagem, tudo isso. [...] eu não posso falar muita coisa por eles, porque eu não estava lá e eles não estavam comigo também. Mas eu acredito que foi bem aceita e está sendo bem aceita (JULIANA).

0 distanciamento, espacial ou afetivo, por parte dos familiares foi notável nesses discursos. Isso nos remete à atual necessidade de ampliarmos nosso enfoque de família, abarcando muito além dos laços de consanguinidade, enfocando principalmente os laços de vínculo e apoio que se formam entre as pessoas. Nos tempos atuais, diante de novas contingências culturais e econômicas, nos quais existe fluidez e fragmentação das relações humanas, a família tem sido recriada de acordo com as demandas dos sujeitos e das possibilidades oferecidas pela sociedade ${ }^{14}$.

\section{Vivendo intensas mudanças no corpo}

Todos os diversos enfrentamentos, até aqui expostos, implicam necessariamente uma mudança de planos para a própria vida cujo curso passa a ser marcado pelas mudanças corporais e afetivas naturais do período gravídico. Assim, para compreender as vivências desses pais na gestação é importante que percebamos as conexões que existem entre as mudanças no corpo e na vida dos dois.

Na gravidez, a mulher, o homem e toda a família expectante revivem emocionalmente sua história de vida. 0 corpo que gesta busca um novo equilíbrio para adapta-se às alterações sofridas nesse período. Todavia, as mudanças não ocorrem apenas ao nível do corpo da mulher, mas também na vida das 'pessoas grávidas', nas suas relações e nos seus sentimentos ${ }^{15}$.

Isso significa dizer que, diante da constatação da gravidez, planejada ou não, os pais constroem novas especificidades na sua dinâmica familiar, nas relações e nos próprios sentimentos quanto à futura posição de mãe/pai. Todas essas modificações emergem paralelamente às transformações do corpo gestacional.

No que diz respeito às mudanças corporais, o que ganhou destaque no discurso das mães foram as modificações na aparência: crescimento do abdome e inchaço; e as alterações como enjôos e vômitos. De um modo bastante peculiar, cada uma atribuiu um significado para essas mudanças corporais.

[...] mesmo antes de eu fazer o exame de sangue para saber se eu estava realmente grávida, acho que eu já sentia, dá pra sentir. Começava a me olhar no espelho, já me achava um pouco mais larga. Eu era magrinha (MARIA).
Maria relata a concretização de sentir-se grávida pelas mudanças, ainda discretas, em seu corpo. A percepção de estar e sentir-se grávida pode existir bem antes da confirmação clínica, sendo captada pela mulher pelas sensações e pela sua imagem corporal'.

As alterações corporais no período gravídico podem também gerar desconforto, como relatado nos trechos a seguir:

Às vezes eu sentia dor nas costas por causa do barrigão, mas depois diminuiu a barriga, porque eu fiquei toda inchada e a barriga tava murcha (JADE).

A minha gravidez foi dureza, olha! No princípio ela enjoou muito, ela vomitava assim, de manhã, de tarde e de noite e de madrugada. [...] Então ela vomitava tudo e eu vendo aquela cena o tempo todo e ela no sofrimento, [...] tem uma hora que você não sabe o que faz para ajudar a pessoa e sofre junto com a pessoa. Entendeu?! Eu quase vomitava com ela para ser um pouco solidário (risos). [...] Aí depois dos quatro meses veio o desespero da barriga, porque eu não conseguia dormir, e a barriga crescendo. [...] Eu estava com seis meses e parecia que estava com nove. [...] Ai eu falava assim: "não, eu tô louca que nasce logo porque eu não aguento mais ficar com esta barriga imensa" (ALESSANDRA e CARLOS).

As dificuldades deste período, expressas como dor, dureza, sofrimento e incômodo, nos remetem às sensações de desconforto. As náuseas e vômitos são os sintomas mais comuns do primeiro trimestre gestacional, sendo que o conhecimento atual aponta para uma etiologia de vários aspectos, ou seja multifatorial, envolvendo mudanças bioquímicas e hormonais, fatores psicológicos, como tensão emocional, oscilações entre aceitação e rejeição da gravidez, participação do marido, dentre outros".

Ao contrário do que normalmente se imagina, de que é somente a mulher que vivencia em seu corpo as alterações da gravidez, o pai também pode ter participação ativa com o seu corpo nesse processo. Carlos, por exemplo, expressou sua preocupação em 'estar junto' e, por conseguinte, suas próprias sensações de desconforto compartilhadas com as de sua esposa. Sua presença nos momentos de dificuldades reflete sua tentativa de ajudá-la a superar, expressa por ele mesmo como solidariedade. Atualmente, o homem participa e se envolve mais ativamente no período gestacional da companheira. Ele vem se fazendo mais comprometido no ciclo gravídico-puerperal, pelas mudanças de comportamento. Então, dependendo da relação afetiva que exista entre o casal, 0 homem-pai pode vivenciar a gravidez com intensidades variadas, levando-se em consideração sua própria personalidade, a imagem cultural da masculinidade, como ele encara sua 
transição de papel (de companheiro e filho para pai) e o seu próprio contexto familiar. Assim como a mulher, ele também pode vivenciar importantes alterações em seu cotidiano ${ }^{16}$.

É, principalmente dormir, porque dormir de barriga para cima é impossível, né! E de lado, qualquer um dos dois lados incomodava. [...] ela ia dormir, ficava dez minutos de um lado, aí virava dez minutos, aí nesses dez minutos, vira, vira, vira, eu também não dormia. Enisso a hora ia passando, ia passando, aí chegava de manhã eu queria ir trabalhar, e eu cheio de sono... (CARLOS).

Outro aspecto digno de nota é a íntima relação que as alterações no corpo físico têm com as alterações afetivas vividas pela mulher durante a gestação. Em geral, estas mudanças afetivas influenciam suas relações com o homem-companheiro

Eu ficava muito nervosa por causa do serviço. Qualquer coisinha ficava nervosa e descontava nele. [...] Ele ficou super calmo, ele ligava e logo tentava me deixar calma (RITA).

Mas eu sempre me aborrecia durante a gravidez. Eu discutia com ele, muito, toda semana, por outras coisas. Ele às vezes saía, eu quero fazer uma coisa, ele quer fazer outra. Então, énormal, coisa de casal mesmo. Às vezes tinha bagunça, eu não queria que bangunçasse, pra ajeitar as coisas (JADE).

As oscilações de humor na gestação são bastante frequentes, geralmente associadas ao aumento da sensibilidade. Assim, um estado de irritabilidade, muitas vezes voltado para o homem-companheiro, é frequentemente observado entre as grávidas, que ficam mais vulneráveis a estímulos externos que antes não a afetavam ${ }^{1}$.

Essas oscilações de humor podem estar relacionadas com as próprias alterações metabólicas e hormonais espećificas da gestação, ou mesmo com as cobranças sociais e econômicas as quais a mulher atualmente é submetida pelo ambiente em que vive. As reações das gestantes estão relacionadas também ao seu contexto cultural, do qual emergem as expectativas em torno da gravidez, os modos de encarar a mulher e seu corpo. A forma como ela vivencia as alterações desse período é moldada por sua própria personalidade e pela experiência familiar ${ }^{17}$.

Depreende-se daí a necessidade de compreender o corpo da mulher grávida em toda a sua magnitude, pois as transformações sentidas na própria imagem a preparam para assumir a nova identidade de mãe.

\section{CONCLUSÕES}

As vivências descritas nesta pesquisa apontam para 0 processo de adaptação e enfrentamento que os pais realizam para a chegada de um novo membro, sendo permeado por significados e representações sobre o bebê que terão e os pais que serão para ele. Essas vivências têm suas raízes na afetividade construída pela mulher e pelo homem, em torno da gravidez, no contexto de suas singularidades e inserção familiar.

Neste estudo, as intensas mudanças na vida estão relacionadas às alterações nos planos, no cotidiano e nos próprios relacionamentos com a família. Já as mudanças no corpo se inscrevem tanto no corpo físico quanto no afetivo. Todos esses fatores estão intrinsecamente conectados e influenciam em maior ou menor grau mediante a própria percepção ou significado que a pessoa atribui ao evento. Por conseguinte, os significados estão diretamente ligados à afetividade. 0 'turbilhão' de afetos em suas dimensões de vida, de uma forma muito singular, circunscrevem e definem suas ações e comportamentos em relação à gravidez.

De um modo geral, essa realidade afetiva que permeia a gestação é pouco valorizada nos âmbitos das unidades de saúde. 0 enfoque biomédico, ainda tão presente na prática, centraliza a atuação do profissional apenas no processo biofisiológico da gestação. Faz-se necessária a adoção também de um enfoque humanizado, para perceber esse fenômeno em sua completude. 0 olhar profissional precisa se estender além do corpo feminino que gesta, buscando o acolhimento da mulher, a inclusão do núcleo familiar no processo de gestação, valorizando a construção da paternidade e das relações familiares na formação do vínculo ${ }^{18}$.

No que tange à enfermagem, nossa relação de cuidado com a gestante e sua família deve valorizar a forma ímpar de enfrentamento de cada ser humano no seu contexto histórico e cultural. Neste sentido, as ações de cuidado devem estar envoltas em valores e compromisso com a pessoa e com a vida humana. 0 cuidado à família expectante deve estar contextualizado nas respostas humanas intersubjetivas às condições de saúde-doença, bem como nas interações ambientepessoa.

Por fim, por meio dos depoimentos dos pais que participaram deste estudo, emergiu a compreensão de que, na trajetória do período gestacional, no qual se experimentam intensas mudanças no corpo e na vida, os enfrentamentos podem oscilar em momentos de desequilíbrio e outros de superação. Nesse entremeio, a afetividade está ligada a essas respostas adaptativas dos pais e da família. Logo, os enfrentamentos são essenciais! 


\section{Referências}

1. Maldonado MT. Psicologia da gravidez. São Paulo (SP): Saraiva; 2000.

2. Lowenkron AM. Maternidades: novas configurações? Rev Bras Psicanal 2001; 35(3): 823-42.

3. Elsen I. Cuidado familial: uma proposta inicial de sistematização conceitual. In: Elsen I, Marcon SS, Silva MRS, organizadoras. 0 viver em família e sua interface com a saúde e a doença. $2^{a}$ ed. Maringá (PR): Eduem; 2004.

4. Nascimento LC, Rocha SMM. 0 cuidado à criança centrado na família. Esc Anna Nery Rev Enferm 2002; 6 (sup1):107-14.

5. Pinto FEM. 0 "mundo do coração": os (novos) rumos de estudo da afetividade na psicologia. Rev Cienc Hum 2004 jul/dez; 10(2): 111-14.

6. Amaral MNCP. Dilthey - conceito de vivência e os limites da compreensão nas ciências do espírito. Trans/Form/Ação 2004; 27(2): 51-73.

7. Denzin NK, Lincoln YS. Introduction: the discipline and practice of qualitative research. In: Denzin NK, Lincoln YS, organizadores. The sage handbook of qualitative research. $3^{\mathrm{a}}$ ed. Califórnia (USA): Thousand Oaks; 2005.

8. Lobiondo-Wood G, Haber J. Pesquisa em enfermagem: métodos, avaliação crítica e utilização. $4^{\mathrm{a}}$ ed. Rio de Janeiro (RJ): Guanabara Koogan; 2001.

9. Ministério da Saúde (BR). Atenção humanizada ao recém-nascido de baixo peso: método mãe-canguru.Manual do Curso. Brasília (DF); 2002.

\section{Notas}

a - 0 presente trabalho recebeu o primeiro lugar do prêmio Ivone Pereira Ferreira, conferido pelo Núcleo de Pesquisa em Enfermagem na Saúde da Mulher do Departamento de Enfermagem Materno-Infantil da EEAN/UFRJ, no $1^{\circ}$ Ciclo de Palestras: "Gestar, Parir e Nascer naturalmente humanizados", em 07 de outubro de 2007. É um recorte da dissertação de mestrado intitulada Encontros afetivos entre pais e bebê no espaço relacional da unidade neonatal: um estudo de caso à luz do método mãecanguru, defendida na UNIRIO, em dezembro de 2007.
10. Arruda DC, Marcon SS. A família em expansão: experenciando intercorrências na gestação e no parto do bebê prematuro com muito baixo peso. Texto Contexto Enferm 2007; 16(1): 120-28. da teoria transcultural de Madeleine Leininger [tese de doutorado]. Rio de Janeiro (RJ): Escola de Enfermagem Anna Nery/ UFRJ; 2003.

12. Silva LR. Cuidado de enfermagem na dimensão cultural e social: história de vida de mães com sífilis [tese de doutorado]. Rio de Janeiro (RJ): Escola de Enfermagem Anna Nery/ UFRJ; 2003.

13. Cavalcanti LB. A lógica da espera. Mente $\&$ Cérebro: a mente do bebê. 2006; 2: 6-13. Série especial. \& Cérebro: a mente do bebê 2006; 4: 6-15. Série especial

15. Guerra MR. Parto natural: nacer bien, derecho de los hijos. Renacer oportunidad de los padres. In: Cáceres HM, Ramírez AMK, Santoro RC, Puchulu SV, editores. Nacer em siglo XXI, de vuelta a lo humano. Humanización del proceso reproductivo mujer-niño-familia. Santiago (CH): Universidad de Chile; 2001.

16. Abreu ASGT, Souza IEO. 0 pai à espera do parto: uma visão compreensiva do fenômeno. Rio de Janeiro (RJ): Ed do Autor; 1999.

17. Bezerra MGA, Cardoso MVLML. Fatores interferentes no comportamento das parturientes: enfoque na etnoenfermagem. Rev Bras Enferm 2005 nov/dez; 58(6): 698-702.

18. Cabral FB, Ressel LB, Landerdahi MC. Consulta de enfermagem: estratégia de abordagem à gestante na perspectiva de gênero. Esc Anna Nery Rev Enferm 2005 dez; 9 (3): 459-65.
11. Santos C. A história de vida de gestantes de alto risco na perspectiva

14. Passos MC. Configurações familiares: os pilares do sujeito. Mente 